\title{
Using Technology in Elementary Mathematics Teacher Education: A Sociocultural Perspective
}

\author{
Sergei Abramovich ${ }^{1}$ and Michael L. Connell ${ }^{2}$ \\ ${ }^{1}$ State University of New York at Potsdam, Potsdam, NY 13676, USA \\ ${ }^{2}$ University of Houston Downtown, Houston, TX 77002, USA \\ Correspondence should be addressed to Sergei Abramovich; abramovs@potsdam.edu
}

Received 31 December 2013; Accepted 21 January 2014; Published 4 March 2014

Academic Editors: B. Marlow and N. R. Riggs

Copyright @ 2014 S. Abramovich and M. L. Connell. This is an open access article distributed under the Creative Commons Attribution License, which permits unrestricted use, distribution, and reproduction in any medium, provided the original work is properly cited.

A central tenet of mathematics education reform is the integral role of technology at all grade levels. The current technological changes combined with the changes in the mathematics content and instructional method require elementary mathematics teachers to be able to design technology intensive lessons for exploration and discovery of these concepts through appropriate computer applications. In actual practice, however, most computer applications provided for mathematics education consist of software designed for a specific educational purpose: the solution in a can scenario. Furthermore, economic constraints often stand in the way of incorporating such special purpose software into an instructional setting. In this paper we will discuss an alternative to this traditional approach which shifts the instructional focus specific computer applications to more sophisticated uses of general purpose software. In particular educational uses of spreadsheets will be developed as an exemplar for this approach.

\section{Introduction}

In the recent past, when we talked about computer applications as pedagogical tools in the mathematics classroom we meant software designed for a particular educational purpose. Yet economic constraints often stand in the way of incorporating special purpose software into an instructional setting and thus challenge computer-enabled mathematics pedagogy and ongoing teacher education programs. A possible way to address the challenge is to shift emphasis from using specific computer applications as teaching and learning tools to retrofitting generic software into an educational environment. Teaching using off the shelf components, as it were. Electronic spreadsheets, for example, are commonly available in schools, colleges, and universities. Yet, a spreadsheet, in order to become a mathematics learning environment, requires from an instructor a number of different skills that are the elements of an individual signature pedagogy $[1,2]$.

How can the introduction of spreadsheets as thinking tools into mathematics classroom be achieved? What does it take for mathematics teachers to develop into technologically minded cognizing and reflective agents [3], capable of advancing computer-assisted signature pedagogy [4] to become a field of disciplined inquiry and, in particular, being skillful in incorporating spreadsheets into the practice of mathematics teaching? This paper will attempt to address these questions from sociocultural perspective.

One of the major assumptions of the current mathematics education reform is that the field of teacher education is amenable to disciplined inquiry. This implies that the way teachers learn mathematics affects the way they will teach it. Appropriate use of computers in the teaching of mathematics may involve the juxtaposition of a student's independent and assisted performances. Computer technology enables both learning perspectives to be mediated by different semiotic means. In particular, an electronic spreadsheet has great potential to be used as a generator of new meanings [4-6]. The spreadsheet-enabled pedagogy has a potential to enhance the teaching of mathematical concepts in the form of assisted performance and facilitate the negotiation of mathematics meaning in a classroom discourse.

However, in such intellectual milieu a teacher's role becomes one of extreme complexity for he or she must be capable of surviving ambiguity in a meaning-making 
environment. This suggests that the spreadsheet-enabled pedagogy is highly dependent on the competency of tomorrow's teachers. Such competence can be developed through an appropriate restructuring of the teacher education programs with a focus on spreadsheets as cognitive tools.

\section{Background}

Traditional mathematics instruction has emphasized using procedures, memorizing algorithms, doing exactly what a teacher wants students to do, and finding the "one right answer." Mathematics, as it was most often presented to students in elementary schools, was not a subject open for discussion, debate, or creative thinking nor were the students encouraged to find more than one way to solve a problem or to seek alternative procedures for carrying out an operation. Limited computational expertise could result from this tradition but little else. Such operation-oriented pedagogy fails to connect students' mathematical activities to mathematical methods available [7]. As a result, students prompted by a teacher follow the algorithms necessary to "solve a problem" but do not and cannot understand why and how those algorithms answer the question at hand. However, according to Poincare, the outstanding French mathematician and physicist of the late 19th to early 20th centuries, with notable interests in mathematics education, students "wish to know not merely whether all the syllogisms of a demonstration are correct but why they link together in this order rather than another" (cited in [8, page 104]). Given this, it was hardly surprising that students became imbued with rigid mental representations of mathematics and its meanings. This is unfortunate because representational flexibility appears to be a thinking tool valued in many domains, including mathematics. Researchers from different fields associate flexible applications of general as well as contentspecific rules and strategies as the indication of higher level of thinking and the manifestation of professional expertise. In particular, one key to successful mathematics teaching and learning is a structural flexibility in choosing and using mental representations of mathematical concepts. To overcome such pedagogical inefficacy, the modern day U.S. educational document, Common Core State Standards [9], proposed six instructional shifts one of which is called "dual intensity." The last two words mean that teaching mathematics should be oriented towards teaching both computational procedures and mathematical concepts that make computations possible [10]. The major strategy that underpins the dual intensity shift is the use of visual representations of mathematical procedures and concepts. Theoretically speaking, this strategy stems from "the [Vygotskian] assumption that mental activity is mediated by culturally derived sign systems" [11, page 227].

At this point a dilemma develops. While we know a great deal about internal representations used by mathematicians, we know far less about how they arrived at those representations [8]. In other words, while we know a fair amount about what it means to be a mathematician, we still do not know very much about how to become a mathematician. If one wants to see a classroom as a mathematical community engaged in conjecturing, debating, discovering, proving, and problem solving $[9,10,12]$ it is important to understand how one can create such a classroom.

Finding that professional mathematicians scored well on tests of computation in their school age, for example, does not mean that we should attempt to implement a mathematics program emphasizing the basic facts only. Rather we must closely examine how competent mathematicians reached that end state and what kind of support system they used. A constructivist approach toward learning has been widely suggested as a way to explain how people acquire new information. In this perspective, learners create their own internal representations of the external world. This view has been widely embraced by the mathematics community but, as many have pointed out, constructivism is a loosely construed concept [13].

Perhaps one of the more telling problems with branches of constructivism that adheres too closely to a representational perspective is that it leads to several problems. First, it falls into the learning paradox: if learning is triggered by internal representations, how does one construct internal mental representations of objects which are more complex than those which already exist in one's mind? Second, since the goal of instruction in representational positions is to provide explicit and transparent representations of mathematical concepts, when instruction fails the teacher's only recourse is to provide more and more explicit and transparent representations. This inevitably leads to its own form of reductionism that may strip mathematical concepts and relationships of their meaning.

The difficulties that representational positions have in offering an adequate description of learning illustrate that descriptions of how one learns may be far more complex than descriptions of existing mental representations. It appears that representational views of learning may, with different wording, lead back to the same problems with mathematics education discussed above. We are still left with some basic foundational questions concerning how children learn and how can we describe that learning.

We are not critiquing representational positions to distance ourselves from constructivism but to clarify directions that offer more, and less, potential for constructivist educators to pursue. As pointed out above, constructivism is a broad umbrella under which many theoretical positions have pitched their tents, and some of those positions lead to contradictions between views of knowledge and an active learner.

Our position is similar to that of Cobb et al. [14] in which they describe mathematics learning as both an individual and a collective activity that transcends the representational view. In the same vein, Schoenfeld [15] has approached the blend of the individual and the collective by suggesting that people may learn mathematical ideas by becoming apprentices in a culturally accepted mathematics practice and that doers of mathematics view themselves as practitioners of mathematical sense-making. Schoenfeld goes on to argue that a student does not need to know all of the basics (e.g., formulas) before he or she begins to think like a mathematician. Rather, a student should be given an opportunity to grapple with real problems instead of doing routine exercises in which 
the territory is already mapped out by a memorized formula. In "real problems", as opposed to routine problems, the strategies, methods, and procedures that one should use to resolve the problem are not clear from the outset. When confronting a real problem, one must actively work through the parts of the problem to arrive at a reasonable solution.

\section{Mathematics Learning as Sociocultural Phenomenon}

The authors' prior research $[6,16-19]$ suggests that, for the case of mathematics, a focus upon action allows for the formation of a natural bridge between current constructivists in mathematics education and sociocultural researchers. Since sociocultural researchers have been influenced by Activity Theory, as explicated by Vygotskian scholars [20], it was probably inevitable that mathematics educators and sociocultural researchers would begin making connections (e.g., $[6,21-25])$. Most sociocultural researchers avoid theories of learning which employ a metaphor separating the mind from what is to be learned. Instead, the concern is with combining the external world with the internal world of the mind in at least two senses: mind is socially distributed and linked to the notion of mediation (e.g., [11, 26, 27]). In these approaches to learning, the Cartesian distinction between the mind and the environment [28] is replaced with an Einsteinian view of ongoing negotiated relationships [29-31].

From a sociocultural perspective, learning of mathematics results from active participation in a culturally accepted mathematics practice and is coconstructed by active interactions between the learner and his or her culture. From this, it might be inferred that if one wants students to think like mathematicians, then one must create a classroom that bears a characteristic of an active participatory mathematics community [32]. Ideally, this should include affective as well as cognitive elements. As Roth and Lee [33] report, even feeling good or feeling threatened by an activity or by the social makeup of the learning environment can impact a learner's ability to effectively learn and contribute. In such an ideal classroom the students are given an opportunity to grapple with real problems by using cultural tools such as manipulatives, geoboards, conventional and nonconventional symbols and representations, and generic and contentspecific software to model mathematics in a variety of formats: diagrammatic, numeric, geometric, graphic, symbolic, and so forth. Successful participation in this community will develop the skills associated with those of experts in the mathematics community [34].

Pólya's [35] famous list of heuristics or, in other words, problem solving strategies suggested a general direction for creative problem solving in mathematics. Both physical and electronic manipulatives provide new means for heuristics and enable students to solve problems through action grounded in trial and error. It might take, however, some efforts to encourage the use of this basic type of learning that mind has invented in elementary mathematics classroom. Students do not have experience in learning from errors. Being anxious to come up with an incorrect answer, they do not believe that it can be internalized and become a thinking device. Outside a classroom, many nonmathematical activities bear a trial and error component. As Bateson [36] puts it: "the unit which shows the characteristic of trial and error will be legitimately called a mental system" (page 465).

The specific approach to the construction of learning environments taken in this paper views individual mental functioning as inherently situated in a social context and mediated by cultural tools and signs such as computers and semiotic devices of software involved. The ideas presented in this paper have been included in several computerenhanced mathematics education courses for preservice and inservice elementary teachers offered by the authors. These ideas affected the teachers' attitudes towards technology and challenged them to extend its use to other topics not "covered" in the courses and eventually to incorporate the ideas learned in the courses in their own teaching.

\section{Mediated Mathematical Action}

The sociocultural approach to mind views humans as coming into contact with the learning environment through the action in which they engage [27]. In turn, the action employs different tools and signs called mediational means. The major claim of the approach is that the mediational means shape human action in many essential ways. Thus, the term mediated action reflects the fundamental relationship between the action and mediational means which it employs. Any mental action directed towards solving a mathematical problem and mediated by appropriate tools and signs may be termed as mediated mathematical action. It is this action that is the major component of environments described below.

Another basic principle associated with the approach is that human mental functioning, particularly mathematical action, originates in the course of communication and thus is inherently social. In a particular sociocultural setting, a contemporary elementary mathematics classroom, a mediated mathematical action can be grounded in the appropriation of the tools of technology such as physical and electronic manipulative, various semiotic devices including mathematical symbols, computer-generated diagrams and graphs, notation systems of software, and iconic and graphic representations. The goal of an instructional discourse in such a setting is to use the mediational means as generators of meaning that, in turn, shapes mathematical action. From the sociocultural perspective "any true understanding is dialogic in nature" (Voloshinov, cited in [27, page 54]), and this claim ties meaning closely to the dialogic orientation of the discourse. As far as an introduction of a computer into the discourse is concerned, it is of paramount importance to provide an environment capable of engaging the student into a purposeful dialogic encounter with the computer. The didactic emphasis of such an environment is to prevent undesirable consequences of authoritative discourse and to allow for the so called internally persuasive discourse that awakens new meaning for a student [27]. Participation in cultural activities provided by a computer environment enables the student to internalize the environment as a thinking tool 
and then move towards structural reorganization of mind that makes it possible to think without such tools. It is this cultural setting that enables "the development of skill with socioculturally developed tools that mediate intellectual activity" [37, page 35].

\section{An Incorrect Answer as a Thinking Device}

In the context of the theory of semiotic (i.e., sign-based) mediation, the word text refers to any meaningful verbal and nonverbal semiotic structure. Text may be as simple as a red signal on a traffic light and as complex as multivolume Encyclopedia Britannica. In a classroom discourse a task and a student's response (answer) to it, are examples of text. Computer-enhanced classroom discourse brings about a possibility for an interactive feedback to a student's response and in that sense it enables for text extension. In that way, the three components of the learning environment-a task, response, and feedback and maybe a refined response-represent a dynamic structure of the text of classroom discourse.

Lotman [38] introduced two functions that text may serve simultaneously, univocal and dialogic. A univocal function of text is to provide constant information that cannot be challenged and may not be open for review. Any question (text) with static meaning structure is not negotiable under any circumstances and it seeks for what is commonly referred to as "the only right answer." A dialogic function of the text is to allow for flexibility in interpretation, enable the negotiation and emergence of new meanings, and encourage its negotiation in a cognitively diverse learning environment.

As far as the Initiation-Reply-Evaluation sequence of intermental functioning is concerned [39], a univocal function of feedback as text provides constant information and it deals with a passive evaluation of an answer per se. On the other hand, a dialogic function of evaluation (feedback) as text focuses on the possibility of invoking a dialogue of a learner with the environment in the case of an incorrect answer. An emphasis on dialogic discourse stems from Vygotskian tradition viewing "social dimension of consciousness (as being) primary in time and in fact (and) individual dimension of consciousness (as being) derivative and secondary" [40, page 30]. There is growing evidence that students' learning of mathematics is more effective in a social milieu of the classroom through conversation, assisted performance, search of alternative solutions, and collaboration. Therefore, when designing computational learning environment in the Vygotskian tradition it is of paramount importance to play out its functional dualism.

In other words, the univocal function of the interactive medium within which a task has been initiated is to provide an inert link between a learner's reply (input) and a computer evaluation (output). By the same token, its dialogic function is to generate new meaning in order to shape a learner's activity. In particular, the dialogic function of the milieu of mediated action is to invoke a follow-up enactive cognitive activity in the case discordance between the input and the output of an information circuit occurring. In such a way, the functional dualism of the environment which appropriates an incorrect answer as a thinking device makes it possible to go beyond the transmission-like model of communication with the unidirectional and monologic structure of its information circuit. Rather than offering just a passive evaluation of a student's answer, this environment brings about an opportunity to learn from an incorrect answer (hypothesis) by contributing to the discourse with a self-generated problem. In such a way the discourse turns out to be internally persuasive; that is, its dynamic structure allows for "interanimation" [27] by a student ardor to resolve a contradiction occurring in the information circuit through a subsequent purposeful activity mediated by the computer.

From this perspective, when computer indicates a discrepancy between the pictorial input and numeric output, a student can regard such result not as negative evaluation but as intermediate external support of the purposeful activity. In such a way, by appropriating an incorrect answer as a thinking device, a learner can ultimately grasp the meaning of what is wrong with this answer.

\section{Illustration 1: Multiple-Choice Problems on Rectangular Grids}

Conference Board of the Mathematical Sciences [41], an umbrella organization comprising 16 professional societies in the U.S., recommended that prospective elementary teachers should be given opportunities to use technology tools "to explore and deepen their understanding of mathematics, even if these tools are not the same ones they will eventually use with children" (page 34). In particular, setting standards for learning mathematics at the primary level in the U.S., Common Core State Standards [9] recommend that students can study decimals "using concrete models or drawings and strategies based on place value" (page 35). One of such models through which operations with decimals can be introduced is a rectangular grid. Using this model, three equivalent representations of rational numbers, one of which is percent, can be discussed. In a more advanced situation, appropriate for the preparation of elementary teacher candidates, the concept of percent can be studied on rectangular grids with the number of cells different from 100. Van den HeuvelPanhuizen et al. [42] claimed "a student's understanding of percentages has its nonnumerical, contextual roots" (page 25 ). This suggests that cognitive interaction between iconic and numeric notations may lead to the recognition of the formal fractional character of the concept of percent.

Consider, for example, 10 colored cells on a 50-cell grid. What percent of the grid is colored? Unlike in the case of a 100 -cell grid, the counting of colored cells on a rectangular grid does not immediately give a percentage number. A possible solution to such a problem involves counting the number of colored cells with a subsequent normalizing of this number to the whole grid. In other words, an activity on a rectangular grid mediated by a nonnumerical representation of a problem situation can lead to an understanding of a numerical structure of the concept of percent as "a relation between two numbers or quantities (expressed) by means of 
ratio" [43, page 150] and, thereby, can support a conscious recognition of its fractional-arithmetic nature.

As described elsewhere [44], with respect to 10 colored cells on a 50-cell grid, a student can be given a multiple choice to select answers from a set of four percentage numbers with the correct answer included: $20 \%, 24 \%, 30 \%$, and $40 \%$. As Figure 1 shows, a student chose $24 \%$ as an answer, which is incorrect. As a result the computer displayed a message asking the student to construct this $24 \%$ on an adjacent 50-cell grid (Figure 1). The activity on the adjacent grid proceeds as in the case of a 100-cell grid described earlier. An interactive feedback displays the percent of the grid colored by the student on the adjacent grid. Once the student has successfully constructed an iconic representation of his/her incorrect answer, the text box will display a message instructing the student to return to the left grid and correct the original guess. Finally, when the student enters the right answer into the answer box, the message in the text box below the adjacent grid disappears and the computer instructs the student to go on to the next problem by displaying a corresponding message in the left text box.

Note that the activity on rectangular grids is similar to what several authors in different disciplines have referred to as the "Hypothesis-Experiment-Instruction" (HEI) method [45-48]. In particular, this method was in mathematics and science classrooms of many Japanese elementary and junior high schools. Indeed, the rectangular grid environment presents students with a question about a percentage form of the colored part of a rectangular grid and gives a set of alternative answers. Then, it provides a computer feedback regarding the correctness of the students' answers and activities aimed at the reflection-justification-discussion of the answers through action. Finally, the environment encourages students to choose an alternative from a given set of answers once again. As in the HEI method, the pedagogy of turning an incorrect answer into a generator of new meaning gives students an opportunity to use an interplay between actions and computer feedback as a thinking device. It is this kind of intermental functioning of a learning environment that is lacking in many classrooms yet, as Wertsch and Toma [49] put it, "has recently been mentioned so often as a desideratum of instruction" (page 173).

\section{Illustration 2: Enhancing Problem Solving in Context by Visual Tools}

The computer's presence in the elementary mathematics classroom confronts mathematics educators with the question about new domains of mathematical activity for students coherent with the help of the computer. Understanding the meanings of manipulative and computational mathematical media is, in the words of Noss and Hoyles [50], "a challenge to create new mathematical scenarios based on what the computer can bring" (page 7). One such scenario stems from a common misconception about percent of a given quantity as an operation on this quantity. More specifically, many students think the increase of a quantity by a given percent is a reversible operation in the sense that the decrease of a new quantity by the same percentage results in the original quantity. This, of course, is not true.

For example, if $\$ 40$ book price was increased by $50 \%$ and then a new price, $\$ 60$, was decreased by the same $50 \%-$ the cutback would not result in the price of $\$ 30$ although many may think that this is the case. In other words, a common misconception is that the operation "increasedecrease" of a number by the same percentage should lead to the same number. Can computer manipulative help a student to overcome this misconception? And if so, how such environment should be structured in order to provide efficient mediation of this type of percentage problems by cultural tools?

With this in mind, an environment was designed in which a set of such problems can be completed through active use of color/erase buttons as cognitive tools. The intention was to engage students in the increase-decrease color activities on a 100-cell grid and then give them a set of equivalent word problems in a symbolic (numeric) form. It was found that while the students were successful in understanding the concept of percent on a 100-cell grid, they often failed to relate the action-bounded activity to a symbolic formulation of a corresponding word problem when the problem was separated from its action-bonded associate in the learning environment. Once again, it is through mathematical action mediated by electronic manipulative as cultural tool that students were expected to construct meaning of percent as nonreversible operation.

However, when word problems on percentage and their action-bounded associates were presented as an objectsymbol unit, the students - a group of 6 graders - could relate their actions on 100-cell grids to the immediate symbolism of the word problems effectively. Figure 2 illustrates the point. This improved environment enabled the students to enhance their understanding of nonreversibility of percentage operation and to think with tools provided by electronic grids. In Vygotskyan terms, it is the incorporation of signs (rectangular grids) in mathematical action that fundamentally transformed the action and allowed for the internalization of thought needed to understand percent as an operation on a symbolic level. This improved environment provided students with tools to think with that enabled them to enhance understanding of percentage as a nonreversible operation.

\section{Concluding Remarks}

As mentioned in the introductory pages, one of the major assumptions of the current mathematics education reform is that the field of teacher education is amenable to disciplined inquiry. This implies the recognition that the way teachers learn mathematics affects the way they will teach it; something that, as Cooney [3] observed, was ingenuously missing in the reform movement of the recent past. Nowadays it has become generally accepted that researchers in the field "appreciate the blurring of content and pedagogy...because...what we learn is encased in how we learned it...(and) think of the teacher as an inquiring mind 

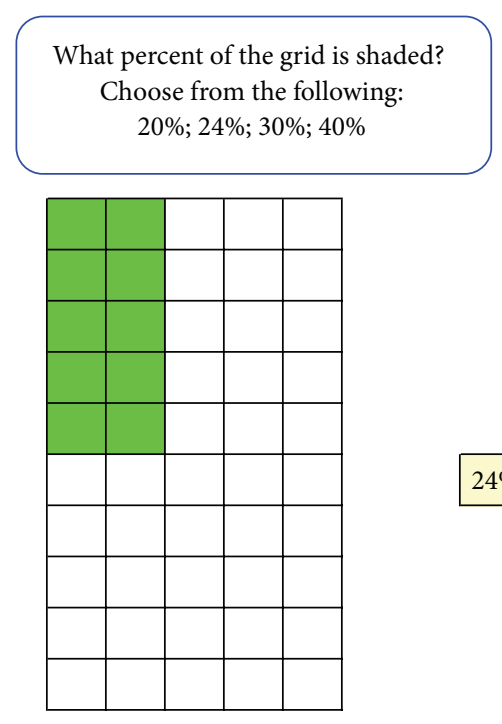

$24 \%$

No. Click the plus button and follow the instructions.

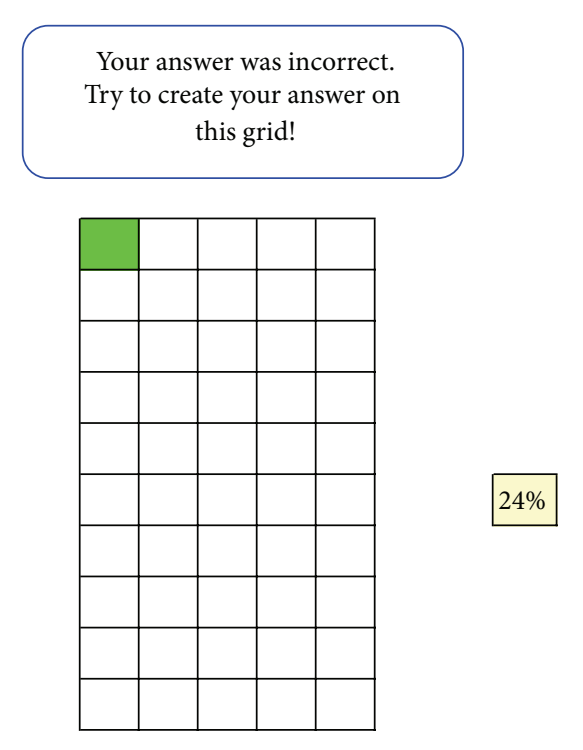

FIGURE 1: A multiple-choice problem on rectangular grids.

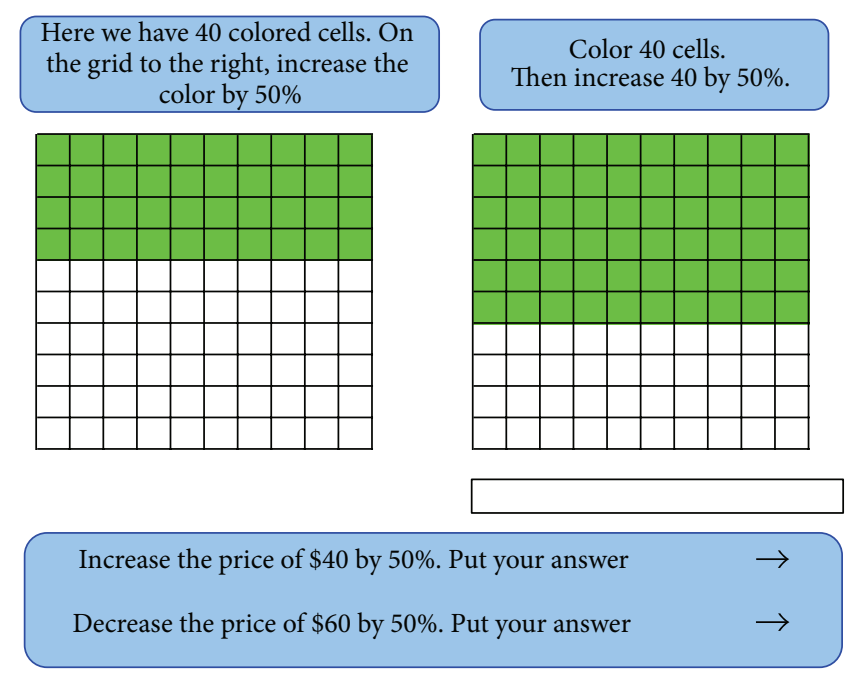

FIGURE 2: Increase-decrease percent environment.

rather than as the object of an inquiring mind" [3, page 627]. With respect to technological component of mathematics teacher education research and development such shift in the emphasis of the reform efforts highlights the importance of analysis of how teachers' views of mathematics and its pedagogy change, evolve, and mature throughout their professional development. Another important question which arises here is how the use of technology affects teachers' belief systems regarding the relationship between mathematical action and mediational means that shape this action.

It should be noted that in the context of a mathematics teacher education course (a site used by the authors to test the above pedagogic ideas) all information regarding notation variety of a spreadsheet as well as mathematical/pedagogical demonstrations can be introduced to teacher candidates not as a final product but in a real time allowing their active involvement in a discourse on syntax, content, and pedagogy of the environment. That is, prospective teachers can experience teaching with technology not through authoritative discourse with essentially monologic assumptions that underline it but rather through a multivocal egalitarian conversation about the birth, development, and implementation of the ideas.

One of the major advantages that technology brings to the classroom is the emergence of an open ended intellectual milieu allowing for a variety of ideas to be explored. In such a setting, technology can be viewed as cultural tools that not only reorganize cognitive processes but also transform 
"For GOD so loved the world that He gave His one and only Son, that whoever believes in Him shall not perish but have eternal life." John 3:16

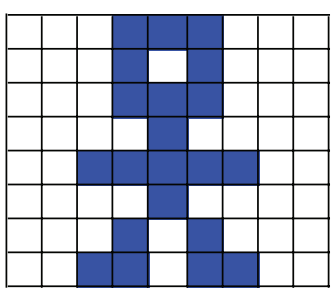

$\frac{21}{72}$

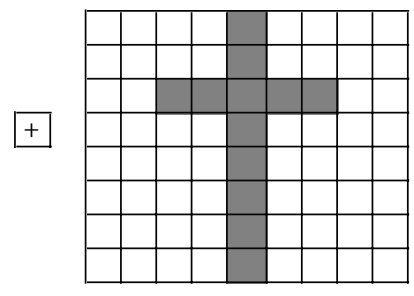

$\frac{12}{72}$

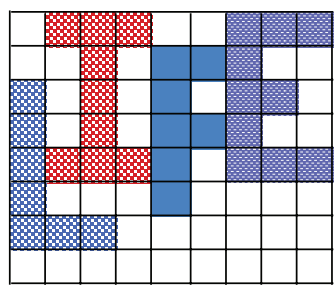

$\frac{33}{72}$

YOUR SUNS ARE FORGIVEN!!!

FIGURE 3: Arithmetic task with "human sense."

classroom social practices [23]. The teacher's role becomes one of extreme complexity for she or he is simultaneously substituted by a computer as an external authority for validation of truth and required to be an adaptive and reflective partner in advancement, capable of surviving ambiguity in a meaning-generative dynamic environment. Thus, teachers' attitudes towards the so structured didactic setting may provide an additional insight into one's conceptualization of new patterns of interaction between content and pedagogy in developing contemporary mathematics teacher education programs.

For example, one teacher candidate, reflecting on the percentage activities described above expressed her belief, "open ended pedagogy is an essential component in a mathematics classroom. Many times a child will pick up on things no one has ever noticed because they are not as tied to viewing the world through the constraints which sometimes limits the views of a more educated person. It is always a joy to view the world through the eyes of a child! Our educational system often is a study of what mankind has learned in the past, and we, teachers, following the tradition try our best to organize and present this body of knowledge to the next generation. Mathematics, however, is a dynamic discipline and must be presented to students as such. We must not restrict their young minds." This is in agreement with another teacher candidate's opinion about patterns of interaction shaped by an egalitarian classroom discourse: "students can become interested and want to explore an avenue or branch of the assignment that the teacher may not have thought of before. Students may inherit enthusiasm not only from the teacher but other students. This (open ended) environment definitely allows for creativity."

A particular example of such creativity was found in a collaborative work of two preservice teachers who demonstrated how rectangular grids can be employed for teaching routine topics in arithmetic. The cartoon displayed in Figure 3 shows an arithmetic task with "human sense" which, in particular, illustrates the fact that the origins of mediated agency can be found in social forms of human existence shaped by one's cultural background. This example manifests the teacher candidates' potential to be reflective and adaptive, capable of understanding how their students "come to know and believe what they do" [3, page 628]. Better still, their own views on teaching and learning warrant their ability to harness semantic multivoicedness of technology-mediated discourse in future pedagogical orientations and decisions.

Patterns of "privileging" [27] found in the teacher candidates' responses to a question, what affected their choice of a topic for a final project, provide yet a further insight into their belief system affected by experiencing firsthand the power of spreadsheet-based technology. For example, one teacher candidate recognized the potential of spreadsheets to reorganize the use of curriculum materials: "I wanted to use Excel in a way that provides students with more than problems from a textbook." This comment indicates the appreciation of using spreadsheets in helping students make mathematical connections: "using a spreadsheet for the discussion of area and perimeter is a very powerful tool because it gives students the opportunity to think about and gain intuitive knowledge about factoring."

To conclude note that this paper does not focus on the details of spreadsheet programming involved in construction of the discussed environments. The awareness of what can be created by using a spreadsheet is, however, of much greater importance than specific syntactic structures involved. Semiotic heterogeneity and syntactic versatility of a spreadsheet make it quite distinct from a canned program. Indeed, different forms of semiotic mediation can be chosen at the discretion of a technology-proficient teacher. Finally, an opportunity to alter verbal mediation at the demand of a particular classroom enables a teacher by using the commonly available tool of technology to address issues pertaining to social and cultural diversity and put to work individual differences that exist in ever heterogeneous community of learners.

\section{Conflict of Interests}

The authors declare that there is no conflict of interests regarding the publication of this paper. 


\section{References}

[1] R. A. R. Guring, N. L. Chick, and A. A. Ciccone, Eds., Exploring Signature Pedagogies, Stylus, Sterling, Va, USA, 2009.

[2] L. S. Shulman, "Signature pedagogies in the professions," Daedalus, vol. 134, no. 3, pp. 52-59, 2005.

[3] T. J. Cooney, "Research and teacher education: in search of common ground," Journal for Research in Mathematics Education, vol. 25, no. 6, pp. 608-636, 1994.

[4] S. Abramovich, J. Easton, and V. O. Hayes, "Parallel structures of computer-assisted signature pedagogy: the case of integrated spreadsheets," Computers in the Schools, vol. 29, no. 1-2, pp. 174190, 2012.

[5] S. Abramovich and E. Cho, "On mathematical problem posing by elementary pre-teachers: the case of spreadsheets," Spreadsheets in Education, vol. 3, no. 1, pp. 1-19, 2008.

[6] S. Abramovich, "Cognitive heterogeneity in computer-mediated mathematical action as a vehicle for concept development," Journal of Computers in Mathematics and Science Teaching, vol. 22, no. 1, pp. 19-41, 2003.

[7] H. Freudenthal, Mathematics as an Educational Task, Reidel, Dordrecht, The Netherlands, 1973.

[8] J. Hadamard, The Mathematician's Mind: The Psychology of Invention in the Mathematical Field, Princeton University Press, Princeton, NJ, USA, 1996.

[9] Common Core State Standards, "Common core standards initiative: preparing America’s students for college and career," 2010, http://www.corestandards.org/.

[10] National Council of Teachers of Mathematics, Principles and Standards for School Mathematics, The Author, Reston, Va, USA, 2000.

[11] C. Fernyhough, "Getting Vygotskian about theory of mind: mediation, dialogue, and the development of social understanding," Developmental Review, vol. 28, no. 2, pp. 225-262, 2008.

[12] National Council of Teachers of Mathematics, Professional Standards for Teaching Mathematics, The Author, Reston, Va, USA, 1991.

[13] P. Cobb, "Where is the mind? Constructivist and sociocultural perspectives on mathematical development," Educational Researcher, vol. 23, no. 7, pp. 13-20, 1994.

[14] P. Cobb, B. Jaworski, and N. Presmeg, "Emergent and sociocultural views of mathematical activity," in Theories of Mathematical Learning, L. P. Steffe, P. Nesher, P. Cobb, G. A. Goldin, and B. Greer, Eds., pp. 3-20, Lawrence Erlbaum Associates, Mahwah, NJ, USA, 1996.

[15] A. H. Schoenfeld, "Learning to think mathematically: problem solving, metacognition, and sense making in mathematics," in Handbook of Research on Mathematics Teaching and Learning, D. A. Grouws, Ed., pp. 334-370, MacMillan, New York, NY, USA, 1992.

[16] S. Abramovich, "Counting and reasoning with manipulative materials: a North American perspective," in The Interfaces of Subjects Taught in the Primary Schools and Possible Models of Integrating Them, N. Petrovic, Ed., pp. 9-20, The University of Novi Sad, Faculty of Education Press, Sombor, Serbia, 2012.

[17] M. L. Connell, "Actions upon objects: a metaphor for technology enhanced mathematics instruction," in Using Information Technology in Mathematics, D. Tooke and N. Henderson, Eds., pp. 143-171, Haworth Press, Binghamton, NY, USA, 2001.

[18] M. L. Connell and S. Abramovich, "New tools for new thoughts: effects of changing the "Tools-to-Think-With" on the elementary mathematics methods course," in Proceedings of the Society for Information Technology \& Teacher Education International Conference, pp. 1052-1057, 1999.

[19] M. L. Connell and M. Bounieav, "Shared recommendations of SSDMA and Constructivism upon technology in mathematics education," The Researcher, vol. 12, no. 1, pp. 21-27, 1997.

[20] J. V. Wertsch, The Concept of Activity in Soviet Psychology, M.E. Sharpe, Armonk, NY, USA, 1981.

[21] P. Cobb, "Cultural tools and mathematics learning: A Case Study," Journal for Research in Mathematics Education, vol. 26, no. 4, pp. 362-385, 1995.

[22] P. Cobb, M. Stephan, K. McClain, and K. Gravemeijer, "Participating in classroom mathematical practices," in A Journey in Mathematics Education Research, E. Yackel, K. Gravemeijer, and A. Sfard, Eds., pp. 117-163, Springer, Dordrecht, The Netherlands, 2011.

[23] M. Goos, "A sociocultural analysis of the development of preservice and beginning teachers' pedagogical identities as users of technology," Journal of Mathematics Teacher Education, vol. 8, no. 1, pp. 35-59, 2005.

[24] E. J. Knuth and D. Peressini, "The dualistic nature of school mathematics discourse," in Proceedings of the 20th Annual Meeting of the North American Chapter of the International Group for the Psychology of Mathematics Education (PME-NA '98), S. Berenson, K. Dawkins, M. Blanton et al., Eds., vol. 1, pp. 227-233, 1998.

[25] J. Moschkovich, "A situated and sociocultural perspective on bilingual mathematics learners," Mathematical Thinking and Learning, vol. 4, no. 2-3, pp. 189-212, 2002.

[26] N. Mercer, "Neo-Vygotskian theory and classroom education," in Language, Literacy and Learning in Educational Practice: A Reader, B. Stierer and J. Maybin, Eds., pp. 92-110, The Open University, Bristol, Pa, USA, 1994.

[27] J. V. Wertsch, Voices of the Mind: A Sociocultural Approach to Mediated Action, Harvard University Press, Cambridge, Mass, USA, 1991.

[28] N. Chomsky, Cartesian Linguistics: A Chapter in the History of Rationalist Thought, Harper and Row, New York, NY, USA, 1966.

[29] W. Bevan, "Contemporary psychology: a tour inside the onion," American Psychologist, vol. 46, no. 5, pp. 475-483, 1991.

[30] P. Cobb, E. Yackel, and T. Wood, "A constructivist alternative to the representational view of mind in mathematics education," Journal for Research in Mathematics Education, vol. 23, no. 1, pp. 2-33, 1992.

[31] L. M. Rosenblatt, "Writing and reading: the transactional theory," Tech. Rep. 13, Carnegie Mellon University, Center for the Study of Writing, Pittsburg, Pa, USA, 1988.

[32] A. Cuoco, E. P. Goldenberg, and J. Mark, "Contemporary curriculum issues: organizing a curriculum around mathematical habits of mind," Mathematics Teacher, vol. 103, no. 9, pp. 682688, 2010.

[33] W.-M. Roth and Y.-J. Lee, “Vygotsky's neglected Legacy': cultural-historical activity theory," Review of Educational Research, vol. 77, no. 2, pp. 186-232, 2007.

[34] M. L. Connell, D. M. Peck, W. Buxton, and D. Kilburn, “True collaboration: an analysis of a conceptual change program in elementary mathematics," in Teacher Education Yearbook: Partnerships in Education II, S. Odell and M. O. 'Hair, Eds., pp. 255-274, Harcourt Brace and Javonovich, New York, NY, USA, 1994. 
[35] G. Pólya, How to Solve It, Princeton University Press, Princeton, NJ, USA, 1945.

[36] G. Bateson, Steps to an Ecology of Mind: A Revolutionary Approach to Man's Understanding of Himself, Ballantine, New York, NY, USA, 1972.

[37] B. Rogoff, Apprenticeship in Thinking: Cognitive Development in Social Context, Oxford University Press, Oxford, UK, 1990.

[38] Y. Lotman, “Text within a text," Soviet Psychology, vol. 24, no. 3, pp. 32-51, 1988.

[39] H. Mehan, Learning Lessons, Harvard University Press, Cambridge, Mass, USA, 1979.

[40] L. S. Vygotsky, "Consciousness as a problem in the psychology of behavior," Journal of Russian and East European Psychology, vol. 17, no. 4, pp. 3-35, 1979.

[41] Conference Board of the Mathematical Sciences, The Mathematical Education of Teachers II, The Mathematical Association of America, Washington, DC, USA, 2012.

[42] M. Van den Heuvel-Panhuizen, J. A. Middleton, and L. Streefland, "Student-generated problems: easy and difficult problems on percentage," For the Learning of Mathematics, vol. 15, no. 3, pp. 21-27, 1995.

[43] F. Depaepe, E. De Corte, P. Op’t Eynde, and L. Verschaffel, "Teaching percentages in the primary school: a four country comparative study," in Powerful Environments for Promoting Deep Conceptual and Strategic Learning, L. Verschaffel, E. De Corte, G. Kanselaar, and M. Valcke, Eds., pp. 147-171, Leuven University Press, Leuven, Belgium, 2005.

[44] S. Abramovich, "Mathematical concepts as emerging tools in computing applications," Journal of Computers in Mathematics and Science Teaching, vol. 19, no. 1, pp. 21-46, 2000.

[45] G. Hatano, "Social and motivational bases for mathematical understanding," New Directions for Child and Adolescent Development, no. 41, pp. 55-70, 2006.

[46] G. Hatano and K. Inagaki, "When is conceptual change intended? A cognitive-sociocultural view," in Intentional Conceptual Change, G. M. Sinatra and P. R. Pintrich, Eds., pp. 407427, Lawrence Erlbaum Associates, Mahwah, NJ, USA, 2003.

[47] J. V. Knapp, “Teaching poetry via HEI (Hypothesis-Experiment-Instruction)," Journal of Adolescent and Adult Literacy, vol. 45, no. 8, pp. 718-729, 2002.

[48] Y. Kobayashi, "Conceptual acquisition and change through social interaction," Human Development, vol. 37, no. 4, pp. 233241, 1994.

[49] J. V. Wertsch and C. Toma, "Discourse and learning in the classroom: a sociocultural approach," in Constructivism in Education, L. P. Steffe and J. Gale, Eds., pp. 159-174, Lawrence Erlbaum Associates, Hillsdale, NJ, USA, 1995.

[50] R. Noss and C. Hoyles, Windows on Mathematical Meaning, Kluwer Academic Publishers, Dordrecht, The Netherlands, 1996. 